\title{
A INTERATIVIDADE NO PROCESSO DE ENSINO E APRENDIZAGEM DE CIÊNCIAS
}

\section{THE INTERACTIVITY IN THE PROCESS OF TEACHING AND LEARNING OF SCIENCES}

Cimara Pereira dos Santos ${ }^{1}$

ORCID iD: $\underline{0000-0001-8807-4810}$

Yuri Expósito Nicot ${ }^{2}$

ORCID iD: 0000-0002-7114-0073

\begin{abstract}
RESUMO
O presente trabalho busca analisar através de uma abordagem qualitativa, tendo como técnica a pesquisa bibliográfica sobre o conceito de interação e interatividade do ponto de vista da implementação de metodologias ativas em sala de aula, que contribuam com a aprendizagem dos alunos e o desenvolvimento de habilidades intelectuais e específicas durante o Processo de Ensino e Aprendizagem das disciplinas de ciências no Ensino Médio. Faz-se uma breve estruturação analítica do termo Interação, de sua semântica em áreas de utilização como Física, Química, Biologia, Sociologia e Informática e a continuação se explana sobre o termo do termo interatividade no contexto do Processo de Ensino e Aprendizagem contemporâneo, permeado de metodologias ativas de ensino e aprendizagem. Destaca-se neste trabalho a intenção de explicar que a interatividade quando promovida no ramo da educação se dá em sua essência por uma efetiva interação entre os principais elementos do Processo de Ensino e Aprendizagem que são: o professor, seus alunos, as metodologias ativas e os recursos didáticos, buscando dialogar como essa facilidade de utilização das ferramentas tecnológicas presentes no cotidiano reflete no Processo de Ensino e Aprendizagem, o que por sua vez proporciona aos alunos, enquanto sujeitos de sua própria aprendizagem, a possibilidade da formação de conceitos científicos.
\end{abstract}

Palavras-chave: Interatividade. Interação. Metodologia. Ensino. Tecnologia.

\begin{abstract}
This work has the purpose of analyzing active methodologies in the classroom environment through a qualitative approach and the use of bibliographical research concerning the concept of Interactivity, the point of view of the implementation of those methodological tools, which contribute to the pupils' educational growth and the development of intellectual and specific skills during the teaching, as well as the learning process of the subjects of science in Secondary Education. First, this research paper will show a brief analytical structuring of the term Interaction and its semantics in areas such as Physics, Chemistry, Biology, Sociology and Computer Science. Then, it will explain the term interactivity in modern education that is present in the active methodologies of the Teaching- Learning Process. It also aims to outline that interactivity, when promoted in the educational environment, occurs as an effective interaction among the main elements of the teaching-learning process, i.e., the teacher, the students, the

${ }^{1}$ Licenciada em Física e atualmente mestranda do Programa de Pós-Graduação em Ensino de Ciências e Matemática (PPG-ECIM) da Universidade Federal do Amazonas (UFAM), Manaus, Amazonas, Brasil. Endereço para correspondência: Av. Torquato Tapajós, 6930, Condomínio Residencial Allegro, Colônia Terra Nova, Manaus, Amazonas, Brasil, CEP: 69093-415. E-mail: cimarapsantos@gmail.com.

2 Doutor em Educação, Professor credenciado na Rede Amazônica de Ensino de Ciências e Matemática (REAMEC) e no Programa de Pós-Graduação em Ensino de Ciências e Matemática (PPG-ECIM) da Universidade Federal do Amazonas (UFAM). Manaus, Amazonas Brasil. Endereço para correspondência: Rua Buritirama, 479, conjunto Ajuricaba, Alvorada, Manaus, Amazonas, Brasil, CEP:69048-490. E-mail: yexposito@yahoo.es.
\end{abstract}


active methodologies and the educational resources, as an attempt to demonstrate that the easiness of the use of the technological and contemporary tools in daily life influences pupils on their educational development. Moreover, interactivity also provides the possibility for students to better their scientific knowledge and to become masters of their own learning process.

Keywords: Interactivity. Interaction. Methodology. Teaching and Learning. Technology

\section{INTRODUÇÃO}

A informação por meio dos canais em que se sustenta é disseminada pelos agentes da comunicação, sendo composta de um emissor e um receptor. A comunicação é algo imprescindível para o homem. A partir do momento em que a vida em sociedade se torna uma realidade, o homem tem a necessidade de se expressar ou perpetuar uma informação importante de alguma forma, surgindo a escrita. Essa forma de comunicação logo passou a ser feita através de escritos em papiros, enviados por mensageiros responsáveis por levar a informação a quem interessasse. Da mesma maneira, surgiram as cartas e tempos depois os telegramas, ou seja, a interação entre emissor e receptor acontecia de forma lenta, mas incessante. Por mais que a distância fosse um empecilho para essa interação, essa dificuldade foi superada, aproximando através de palavras escritas informante e informado.

Antes dos adventos e da popularização da internet, a difusão da informação se dava apenas através da página impressa. Desse modo, os jornais impressos assumiram por muitos anos o papel de emissor/informante. Posteriormente surgiram os veículos de rádio e os canais de televisão. Atuando do outro lado do canal de comunicação como receptor/informado, as pessoas (leitores, ouvintes e telespectadores) passaram a ser consumidores cada vez mais ávidos por informações. (VAN DAL, 2013)

No entanto, mesmo com o surgimento de tais aparatos considerados até então altamente tecnológicos, não se tinha uma relação direta entre emissor e receptor da informação. O emissor não tinha como saber qual a reação do receptor ao obter a mensagem repassada. Eventualmente, só eram realizadas pesquisas de satisfação ou a chamada pesquisa de ibope, através das quais se podia ter um feedback acerca das impressões do receptor para assim tentar se ajustar às situações informadas, buscando sempre desenvolver algo mais atrativo para o público destinatário.

Já com o surgimento da internet e dos recursos tecnológicos que ajudaram a torná-la parte do cotidiano das pessoas, surgiu a oportunidade de aproximar o emissor do receptor, fazendo com que eles pudessem construir uma interação quase que instantânea, tornando assim, esse processo de informação mais produtivo para ambas as partes. Com isso passou a ser 
comum o uso dos termos interação e interatividade no mundo da informática. Logo, a apropriação do termo interação está geralmente relacionada a algo tecnológico, dando a entender que, se tem interação promove a interatividade (SILVA, 2009).

$\mathrm{Na}$ atualidade, Empresas de marketing e propaganda, fora do contexto educacional, têm utilizado o termo interação com fins de alcançar maior prestígio junto ao consumidor (LIMA, 2012), buscando entrelaçar a ideia do interativo como sendo uma concepção moderna ou pensado especialmente para o consumidor, ou usuário. Exemplos disso são banners com movimentos, sons, ou produtos que dispõem da tecnologia touchscreen, como celulares smartfones, aparelho de televisão, computadores, etc. Por isso, cabe perguntar: Mas será que tudo o que traz interação promove mesmo a Interatividade? Para responder essa questão, cabe aqui uma breve análise dos termos interação e interatividade, em outras áreas de atuação.

A metodologia utilizada partiu de uma revisão bibliográfica sobre os conceitos de interação e interatividade. É de extrema importância deixar claro que a análise desses termos tem a intenção de fazer uma reflexão quanto sua aplicabilidade no ramo da educação, entender como sua usabilidade vem gerando impactos em salas de aula, sobretudo no que se refere ao uso de ferramentas tecnológicas que atualmente fazem parte do dia a dia da maioria dos alunos e professores. Após a apresentação do que significam os termos interação e interatividade no plano educacional, faz-se uma reflexão da aplicabilidade da Interatividade na Educação, quando desenvolvida junto a metodologias ativas e, por fim, uma reflexão do ensino através de competências que favoreçam a interação e a interatividade em sala de aula.

\section{CONCEITO DE INTERAÇÃO E INTERATIVIDADE}

O termo interação é encontrado em várias áreas do conhecimento. Serão destacados nesse trabalho campos onde esse termo se destaca, visto que não é intenção precípua um aprofundamento conceitual sobre tais campos. Para se considerar um exemplo, na Física, ciência que se dedica a estudar os elementos da matéria e suas interações mútuas, físicos têm se dedicado incansavelmente a explicar as propriedades da matéria e fenômenos naturais observáveis e não observáveis (ALONSO; FINN, 2018). De acordo com (CUNHA, 2018), existem quatro tipos de interações fundamentais: a interação gravitacional, interação eletromagnética, interação forte e interação fraca, e a partir dessas, pode-se nortear todas as interações entre os corpos. Ou seja, na Física, as interações das forças fundamentais da natureza são a base para a explicação de qualquer fenômeno físico já observado no universo. 
Na Sociologia, observa-se a dedicação ao estudo das interações sociais entre pessoas e como isso os afeta direta ou indiretamente. Nesse caso, o estudo sociológico se preocupa em estudar como a interação afeta as relações sociais e influenciam em seu comportamento, enquanto integrantes de uma sociedade, em sua cultura, tentam construir sua própria personalidade (ALVES, 2017). As interações sociais são responsáveis em sua totalidade para o desenvolvimento do ser humano em todos os aspectos de sua vida. Sua personalidade é desenvolvida de acordo com as influências do meio no qual está inserido.

Em Química, encontra-se a aplicabilidade do termo interação quando se estudam as chamadas Interações Intermoleculares, que podem ser descritas de acordo com suas características. Entre essas características, existem as interações iônicas, interações do tipo dipolo-dipolo, dipolo permanente ou induzido, interação de dispersão e pontes de hidrogênio, entre outras. Um exemplo dessas interações são fenômenos comuns no nosso cotidiano, como a capilaridade e a tensão superficial da água. Basicamente, como enfatiza o autor, "uma interação Química significa que as moléculas se atraem ou se repelem entre si, sem que ocorra a quebra ou formação de novas ligações químicas. Essas são chamadas de interações não covalentes ou interações intermoleculares" (ROCHA, 2001, p.31).

$\mathrm{Na}$ Biologia, tem-se o estudo das Interações Ecológicas, que, por sua vez, estão diretamente ligadas à história evolutiva das espécies, desde a origem da vida, sempre modificando de alguma maneira as chamadas comunidades biológicas. Quando organismos interagem entre si, seja compartilhando alimento, disputando território, acasalando com a mesma espécie (relações intraespecíficas) ou com espécies diferentes (relações interespecíficas) tais organismos são modificados. Essas interações podem também acarretar benefícios ou malefícios para uma, ou ambas as espécies. (LOTUFO, 2018). No campo da genética, existe também a chamada interação gênica, responsável pelas características fenotípicas como, por exemplo, cor dos olhos, cor da pele, pelo, altura, entre outras, que são determinadas pelo resultado de uma interação entre alelos, conforme definem os autores, "quando dois ou mais pares de alelos atuam na determinação de uma mesma característica, o fenômeno é chamado interação gênica” (LINHARES; GEWANDSZNAJDER; PACCA, 2016, p. 57).

Já na Informática, a interação é proporcionada basicamente entre homem e máquina. Existem estudos sobre a Interação Homem-Computador (IHC) que definem essa interação como sendo "enfoque mais amplo com novos campos de estudo envolvendo a comunicação entre usuários e computadores ou outros tipos de produtos" (REBELO, 2010, p. 14). A autora também traz um significado para o termo Interface, definindo-o como sendo algo facilitador ou intermediador da interação entre homem-computador. Além disso, separa o termo em dois 
aspectos, interface física (Ex.: cabos, placas, mouse) e interface lógica (Ex.: softwares, gráficos). Basicamente, na área de IHC, fica bem definido que a interação acontece diretamente com o usuário das ferramentas tecnológicas disponíveis. Atualmente, essas ferramentas permitem uma combinação de várias interfaces, que podem, se desejado, aumentar o grau de dificuldade da interação entre homem e máquina. Ao fazer essa análise em diferentes áreas de conhecimento, pode-se observar que o termo interação está sempre associado a trocas entre dois ou mais componentes, sejam eles moléculas ou partículas, como no caso da Química e da Física, entre os seres humanos em suas relações sociais necessárias para seu desenvolvimento enquanto cidadão, ou entre os demais seres vivos que compõe nosso ecossistema. Tais componentes geralmente se inserem em uma troca de estímulo-resposta. Partindo desse ponto, pode-se então fazer uma análise do termo interatividade no ramo da informática, para posteriormente verificar sua aplicabilidade no ramo da educação.

Quando se pesquisa sobre o significado do termo interatividade, muitos autores afirmam que surgiu desde o desenvolvimento da comunicação em massa. Segundo Gobbi; Bernadini (2013), o termo surgiu no século XX, oriundo do neologismo inglês "interactivity", que designa uma interação entre humanos e computador, na qual computador faz uma relação de interatividade com o homem. De acordo com Salles (2016), é uma derivação do termo interação, sendo interatividade a ação de interagir.

Os termos Interação e Interatividade são sinônimos, sendo que a interação está associada à troca entre os sujeitos, e a interatividade está associada diretamente a ferramentas tecnológicas atuais. Os dois autores concordam que a interação está essencialmente ligada às relações sociais entre os sujeitos e a interatividade entre máquina e sujeito. Já Silva (2001) diz que a interatividade está diretamente relacionada ao surgimento da cibercultura, de uma nova era comunicacional baseada na internet, e enfatiza que muitos autores associam erroneamente interatividade com a interação passiva, que é proporcionada pelos canais de televisão, rádio, etc., como revela o autor:

Interatividade significa libertação do constrangimento diante da lógica da transmissão que predominou no século XX. É o modo de comunicação que vem desafiar a mídia de massa - rádio, cinema, imprensa e tv - a buscar a participação do público para se adequar ao movimento das tecnologias interativas (SILVA, 2001, p. 11).

O autor expõe aqui, basicamente, uma relação importante de dois tempos na história da comunicação que apontam bem a diferenciação entre interação e interatividade na comunicação. O primeiro antes do surgimento da internet, no qual os canais de mídia em massa deixavam os agentes da comunicação dentro de uma passividade; o conteúdo era passado pelo 
emissor, sem que esse soubesse do verdadeiro impacto da informação que chegava até o receptor, pois, o receptor não tinha como imediatamente expor seu ponto de vista em resposta ao emissor. Isso se dá de forma diferente, após o surgimento e popularização da internet, uma vez que a resposta pode ser dada no instante do recebimento da informação, através de interfaces como chats, comentários em caixas de diálogo presentes nas redes sociais, conforme os autores:

\begin{abstract}
A interatividade é um dos grandes ganhos proporcionados pelas ferramentas da web 2.0. Um espaço de produção é aberto aos usuários da rede através dos blogs, redes sociais, wikis e nuvens de armazenamento de dados. A informação deixa de ser encarada com o viés unilateral de distribuição e passa a ser tratada como comunicação e troca (ZANETTI; LUZIVOTTO, 2018, p. 135).
\end{abstract}

Ainda segundo Silva (2001), a interatividade tem significado na comunicação entre interlocutores humanos, entre homem-máquina, mas ela pode acontecer também entre usuário e serviço, sendo que, para ter efetividade, é necessário que essas interlocuções obedeçam a pelo menos duas especificações: "1. A dialógica que associa emissão e recepção como polos antagônicos e complementares na co-criação da comunicação; 2. A intervenção do usuário ou receptor no conteúdo da mensagem, ou do programa aberto a manipulações e modificações" (SILVA, 2001, p. 5).

Dessa maneira, não existe passividade de nenhuma das partes. O diálogo não é parcial e sim bilateral, abrindo espaço para um ciclo contínuo, onde o emissor e receptor podem fazer uma troca de papéis dinâmica. As possibilidades se tornam inúmeras e os debates criados podem tomar rumos inesperados, o que gera uma afluência cada vez maior quando se trata de comunicação e troca de informações.

O autor Primo (2000), em seus estudos relativos à interatividade, traz à tona a discussão sobre a diferenciação de interativo e reativo. Segundo ele, aquilo que somente responde a estímulos pré-determinados é considerado apenas reativo, como vem a ser o caso de um jogo de videogame, onde o usuário, independentemente da escolha feita, responde apenas a "regras" pré-determinadas pela programação do jogo. No mesmo viés, outro autor diz:

Boa parte dos equipamentos hoje experimentados ou já comercializados como interativos são, na verdade, apenas reativos. Os videogames, por exemplo, solicitam a resposta do jogador/espectador (resposta inteligente em alguns casos; resposta mecânica na maioria dos outros), mas sempre dentro de parâmetros que são as 'regras do jogo' estabelecidas pelas variáveis do programa. Isso quer dizer que nas tecnologias reativas não há lugar propriamente a respostas no verdadeiro sentido do termo, mas a simples escolhas entre um conjunto de alternativas preestabelecidas. (MACHADO, 1998, p. 26) 
Nesse caso não tem espaço para a interatividade, pois as possibilidades de interação entre homem-máquina são limitadas por regras estabelecidas pela interface do jogo. E, mesmo com o avanço da tecnologia, os videogames, apesar de apresentarem interfaces bem mais sofisticadas, ainda assim continuam sendo apenas reativos em relação ao usuário e vice-versa. Um exemplo é a chamada Realidade Virtual (VR), onde estímulo ao usuário é feito através de códigos de programação muito bem estabelecidos com a intenção de provocar determinada reação no mesmo, restando somente ao usuário reagir de acordo com as sensações que a interface lhe proporciona.

\section{INTERATIVIDADE NA EDUCAÇÃO}

A educação vem sendo alvo de constantes inovações didáticas que demonstram as tentativas de mudança e existe uma necessidade para tal, uma vez que a sociedade como um todo foi afetada direta ou indiretamente pelos avanços da tecnologia. Os tempos são outros, as gerações recentes pensam e reagem de maneiras distintas das gerações passadas. As escolas, que em outras épocas desempenhavam uma função conteudista, não exercem mais esse papel. O professor não é mais o único detentor do conhecimento. Pelo contrário, os alunos e alunas já chegam à sala de aula com conteúdos que seus professores desconhecem, devido à velocidade da transmissão de informação. As mídias ou redes sociais como YouTube, Facebook, Instagram, blogs e outras trazem todo tipo de informação quase que instantaneamente ao aluno. Todo conteúdo que antes era acessado apenas por meios físicos como a sala de aula ou bibliotecas públicas está agora disponível na tela do smartphone, nas pesquisas rápidas na internet e muitas vezes chegam sem mesmo ser solicitado.

No entanto, mesmo com toda a facilidade proporcionada pela internet, o professor não se torna desnecessário e as demais ferramentas físicas de pesquisa também não deixam de ter utilidade no âmbito educacional. Isso é corroborado pelos autores Coutinho; Villalba (2013), ao afirmarem que, em meio às tecnologias acessíveis, ainda há a necessidade de uma nova visão, de encarar as coisas de uma outra forma, a fim de considerar novas perspectivas, para estar aberto a outras possibilidades em relação aos desafios postos no trabalho docente. Por isso, mesmo que as mídias sociais e a internet estejam sendo sem sombra de dúvida algo tão impressionante e prático, toda essa transformação traz consigo aspectos positivos e negativos quando se trata do processo de ensino e aprendizagem. Cabe então aos profissionais da área da educação perceber os aspectos negativos a fim de buscar uma solução e se adequar aos novos tempos, utilizando-se habilmente das vantagens que as ferramentas tecnológicas proporcionam. 
Podemos citar aqui ao menos um aspecto negativo e um positivo das mídias sociais na educação: negativo: o conteúdo pode chegar ao aluno de forma fragmentada e generalizada; positivo: a praticidade do acesso aos conteúdos dá ao professor e ao aluno um leque de possibilidades que podem ser aproveitadas como nunca sequer imaginado antes.

Dessa maneira, a interação entre os sujeitos pertencentes ao processo de ensino e aprendizagem é de essencial importância quando se fala em educação, temos a interação professor-aluno, aluno-professor e aluno-aluno que trazem principalmente troca de experiências fundamentais no processo de ensino e aprendizagem. Já quando se fala de interatividade, considerando os aspectos que foram citados anteriormente por Silva (2001), nos traz vantagens relevantes em muitos aspectos, principalmente na educação observando que estamos na era dos chamados nativos digitais, conceituado por Prensky (2001), como aqueles que nasceram imersos nos avanços tecnológicos do século XX, com acesso e facilidade em manusear artefatos tecnológicos e por consequência, desenvolveram a capacidade de realizar múltiplas tarefas, passando a pensar e processar informações de maneira diversificada.

Em concordância com autor (que autor?), pode-se dizer que a geração atual se encontra preparada para lidar com aparatos tecnológicos. Trata-se inegavelmente de uma geração na qual práticas pedagógicas devem ir além do papel e caneta, considerando que a tecnologia quando bem utilizada serve para estimular o aprendizado. Como dizem os autores Vargas L.; Vargas G.; Castro (2016), ambientes diferenciados atrelados ao uso de mídias sociais e ferramentas propiciadas pela internet ajudam a desenvolver a cognição e consequentemente a interação. Assim, sob essa ótima, ganha particular relevância a utilização das ferramentas tecnológicas para promover a interatividade.

No entanto, não basta os alunos saberem manusear as ferramentas sem estarem atentos ao seu principal objetivo, que é aprendizado. As informações chegam a todo instante, muitas vezes de maneira parcial e fragmentadas, podendo o aluno fazer generalizações que, quando se tratam principalmente do ensino de Ciências, não são aceitas. Cada caso é particular e o aluno só irá compreender se o conteúdo for devidamente pesquisado e debatido em todos os seus aspectos. Logo, o professor deixa de exercer a função de "palestrante", onde o conteúdo é debatido unilateralmente. Ele agora se torna mediador, alguém que está ali para compartilhar e partilhar seus conhecimentos para que não se perca o foco. Como os autores Neto e Mendes (2013) enfatizam:

Não se pode mais continuar acreditando que basta investir em tecnologia para a escola, fornecendo-lhes equipamentos ou computadores, sem compreender o processo pedagógico de ensino e aprendizagem, que relaciona as novas tecnologias às outras 
competências para os professores e maneiras de aquisição e apropriação de saberes pelos educandos. Mais que isso, é necessário desenvolver nos alunos o potencial para aprendizagem colaborativa, em que pesem os processos de interação e interatividade, aproveitando-se dos novíssimos suportes da cibercultura que se apresentam todos os dias (NETO; MENDES, 2013, p. 25).

Dessa forma, percebe-se que para a inclusão parcial ou total da utilização de tecnologias em sala de aula para facilitar a interatividade e assim a interação de professor-aluno de maneira mútua é necessário que ambas as partes estejam falando uma só língua. O professor não pode estar aquém da evolução dos processos pedagógicos. Segundo Souza et al, (2013), o professor, quando trabalha em ambientes virtuais, não pode manter o paradigma da sala de aula tradicional, pois o diferencial dos ambientes virtuais é sua capacidade de proporcionar uma maior interação entre os sujeitos, isso porque as práticas pedagógicas nesses ambientes estão baseadas em colaboração, inovação, afetividade e autonomia.

\subsection{Metodologias Ativas e Interatividade}

Em uma busca realizada nas literaturas publicadas entre os anos de 2015 e 2019, sobre o conceito de metodologias ativas, fica evidente a concordância entre os autores como Morán (2015), Peixoto (2016), Fonseca; Neto (2017); e Valente; Almeida; Geraldini (2017) que, devido à inquietação e críticas ao modelo de ensino tradicional por parte dos pesquisadores em educação ao longo dos anos, surgiram novos modelos que visam à autonomia dos alunos no processo de ensino e aprendizagem, chamados de Metodologias Ativas.

Uma metodologia ativa é totalmente centrada no aluno, que passa a ser protagonista de seu próprio aprendizado, visando à sua autonomia, maior participação e possibilitando uma liberdade na construção de seu conhecimento. O professor, por sua vez, passa a ser um agente de colaboração, sendo o mediador do aprendizado e realizando observações, orientações e avaliações ao longo de toda a prática pedagógica, com o objetivo de identificar possíveis necessidades e reconhecer a evolução no aprendizado. Assim, foram desenvolvidos tipos de metodologias ativas que tentam integrar tais preceitos. De acordo com Pinto (2019), todas essas vertentes podem utilizar ferramentas tecnológicas em seu desenvolvimento, como é o caso da aprendizagem baseada em projetos, aprendizagem baseada em problemas, aprendizagem entre pares ou times, sala de aula invertida, entre outras.

A tecnologia, integrada a essas metodologias, proporciona múltiplas possibilidades, como a facilidade de encontrar e compartilhar informações a partir do uso da internet e de plataformas de mídias sociais. No entanto, é preciso estar atento para a promoção da interação 
bilateral entre os sujeitos envolvidos nesse processo, efetivando assim a interatividade, uma vez que ela ocorre quando o envolvimento de determinados sujeitos em uma dinâmica é baseado no uso de ferramentas tecnológicas disponíveis, permitindo a interação entre si, objetivando a construção de conhecimento, mesmo que os sujeitos estejam em contato através de plataformas on-line ou de forma presencial.

\title{
3.2 O ensino através de competências, partindo de indicadores que favorecem a Interação e a Interatividade em sala de aula.
}

De acordo com Wittaczik (2007), diante das mudanças da sociedade e suas novas exigências modernas, as Américas e países europeus começaram a se preocupar com propostas educacionais que se adequassem a esse novo mundo. Dessa maneira surgiu a pedagogia por competência. Do mesmo modo, no Brasil, as propostas curriculares passaram ter em foco as competências.

Menezes e Santos (2001) destacam que para o Ministério da Educação:

\begin{abstract}
Competências são ações e operações que utilizamos para estabelecer relações com e entre objetos, situações, fenômenos e pessoas que desejamos conhecer. São operações mentais estruturadas em rede que mobilizadas permitem a incorporação de novos conhecimentos e sua integração significada a esta rede. (MENEZES; SANTOS 2001, p. 1)
\end{abstract}

Em relação aos profissionais da educação, Garcia e colaboradores (2011) comentam que, devido a todas as mudanças no modelo de ensino, as quais criticam e abandonam o método tradicional, passando a estabelecer novas práticas com o auxílio das tecnologias, exige-se dos profissionais novas competências a serem repensadas e colocadas em prática, uma vez que as competências de outrora tiveram de se adaptar a uma nova realidade pedagógica. Os mesmos pesquisadores estabelecem ainda quais competências seriam necessárias para que o professor fosse capaz de trabalhar com metodologias centralizadas em novas tecnologias educacionais. Segundo esses autores, o domínio das ferramentas tecnológicas nas quais se pretende trabalhar, quando o assunto é educação, deve envolver saber fazer aplicações utilizando a internet, saber reconhecer ferramentas que possam potencializar a relação no Processo de Ensino e Aprendizagem, entre outras competências.

No que se refere à interação e à interatividade, mesmo que o professor saiba dominar todos as ferramentas tecnológicas e seja capaz de incentivar seu uso por parte dos alunos, é necessário ir além. Ele precisa ter a competência para desenvolver dinâmicas e estabelecer conexões entre tais ferramentas e as relações interpessoais entre os próprios alunos e entre o 
docente e os alunos. O uso puramente mecânico de ferramentas tecnológicas, mesmo que usadas para uma simples pesquisa de conteúdo, não é efetivo se não houver troca de informações interpessoais, pois é nessa interação entre os sujeitos da aprendizagem juntamente à interatividade por meios das ferramentas tecnológicas que irá de fato ocorrer a construção do conhecimento.

Outra competência seria a de saber conduzir essas dinâmicas incentivando o compartilhamento de informações por parte de todos os integrantes, sendo sensível a fatores como timidez e insegurança por parte dos alunos. É necessário enfatizar que todos precisam compartilhar, pois não existe pensamento certo ou errado, existindo sim uma troca para a construção de conhecimento individual a partir de um todo. Também é necessário saber reconhecer as limitações dos alunos quanto às suas habilidades tecnológicas e propor alternativas para que não eles não sejam prejudicados, pois, mesmo sendo pertencentes à era tecnológica, isso não quer dizer que todos sabem utilizar todas as ferramentas existentes, podendo haver uma certa facilidade, mas não um domínio total do mundo digital.

\section{CONSIDERAÇÕES}

Fazendo a análise de Interação, não podemos deixar de observar que é um conceito de ampla utilização e complexo quando se trata de dar um único sentido ao seu significado. O termo é aplicável em áreas distintas com toda sua relevância. A Interatividade traz quase que os mesmos aspectos relacionados à Interação, uma vez que sua semiótica se entrelaça com outros adjetivos, fazendo com que essas duas palavras venham a ser sinônimos. No entanto, mesmo quando ocorre a interação, a interatividade pode não estar presente, considerando que a interação está ligada muitas vezes às trocas de processos biológicos ou de natureza física. Já a interatividade, por sua vez, está interligada quase que diretamente às relações humanas mediadas por ferramentas de pesquisa e comunicação. Os autores Gobbi; Bernadini, (2013), Silva, (2001), e Zanetti; Luzivotto (2018) afirmam que os avanços tecnológicos a partir século XX ocasionaram uma bilateralidade na comunicação. Receptor e emissor passaram a interagir mutuamente, criando a oportunidade de trocas de experiências e informações que são de suma importância no desenvolvimento do ser humano.

Com relação ao uso da interatividade na educação, para que ela seja utilizada de forma efetiva, é de suma importância que ocorra uma real interação entre professor-aluno e alunoaluno ao utilizarem as ferramentas de pesquisa disponíveis. Deve-se levar em consideração nesse processo os desafios e possibilidades aos quais esses agentes estão expostos. Isso porque 
o real objetivo de uma educação baseada na interatividade é a formação de cidadãos autossuficientes e acima de tudo críticos. Para que isso ocorra é importante estar disposto e preparado para construir uma nova maneira de ensinar e aprender. Um ensino e aprendizagem centralizado nas metodologias ativas, englobando as competências necessárias para promover a interatividade em sala de aula. Essas ações pedagógicas podem vir a promover um processo de ensino e aprendizagem efetivo, que se alinha à realidade da contemporaneidade. Afinal, a educação não é um processo estático. Seu real objetivo é ofertar novas maneiras de se refletir sobre um mundo que está sempre em constante evolução.

\section{REFERÊNCIAS}

ALONSO, M.; FINN, J.E. Física: um curso universitário. Tradução de Mario A. Guimarães et al. São Paulo: Blucher, v. 1, 2018. 508 p.

ALVES, M. A. D. A importância das interações sociais no desenvolvimento das competências sociais. Instituto superior de Educação e Ciências. Lisboa, p. 89. 2017.

CUNHA, B. C. O caráter de uma força fundamental. Saense. Publicado em 23 de janeiro de 2018. Disponível em: 〈http://www.saense.com.br/2018/01/o-carater-de-uma-forcafundamental/>. Acesso em: jan, 2019.

FONSECA, S. M.; NETO, J. A. M. Metodologias ativas aplicadas a educação a distância: revisão de literatura. Revista EDaPECI, São Cristóvão - SE, v. 17, n. 2, p. 185 - 197 mai/ago 2017. Disponível em: <https://seer.ufs.br/index.php/edapeci/article/view/6509/pdf>. Acesso em: jan. 2019.

GARCIA, M. F. et al. Novas competência docentes frente às tecnologias digitais interativas. Revista Teoria e Prática da Educação, v. 14, n. 1, p. 79-87, jan/abr 2011. Disponível em: <http://ojs.uem.br/ojs/index.php/TeorPratEduc/article/view/16108/8715>. Acesso em: abr. 2019.

GOBBI, M. C.; BERNARDINI, G. Interatividade: um conceito além da internet. Revista Geminis, v. 4, p. 42-56, 2013. Disponível em: <http://www.revistageminis.ufscar.br/index.php/geminis/article/view/143>. Acesso em: jul. 2018.

LINHARES, S.; GEWANDSZNAJDER, F.; PACCA, H. Biologia Hoje. 3. Ed. São Paulo: Ática, 2016.

LIMA, P. A. de. Impacto dos formatos tradicional e interativo de propaganda na atitude e intenção de compra dos consumidores. 2012, 76 f. Dissertação (Mestrado em Administração) - Universidade de Brasília, Brasília, 2012. Disponível em: < https://repositorio.unb.br/handle/10482/12297?mode=full>. Acesso em: jul. 2020.

LOTUFO, T. M. D. C. Interações Ecológicas. Instituto Oceanográfico, 2018. Disponível em: <http://www.io.usp.br/index.php/infraestrutura/museu-oceanografico/29- 
portugues/publicacoes/series-divulgacao/vida-e-biodiversidade/821-interacoes-ecologicas>.

Acesso em: jan. 2019.

MACHADO, A. Pré-cinemas e pós-cinemas. Campinas: Papirus, 1998.

MENEZES, E. T. D.; SANTOS, H. D. Verbete competência. Dicionário Interativo da Educação Brasileira - Educabrasil, São Paulo: Midiamix, 2001. Disponível em: <https://www.educabrasil.com.br/competencia/>. Acesso em: mar. 2019.

\section{MORÁN, J. Mudança a educação com metodologias ativas.}

Coleção Mídias Contemporâneas Convergências Midiáticas, Educação e Cidadania: aproximações jovens, v. 2. São Paulo. 2015. Disponível em: 〈http://rh.newwp.unis.edu.br/wpcontent/uploads/sites/67/2016/06/Mudando-a-Educacao-com-Metodologias-Ativas.pdf>.

Acesso em: jan. 2019.

NETO, A. S.; MENDES, G. M. L. Novas fronteiras para a educação online. Revista educação e Fronteiras On-Line, v. 3, p. 22-46, mai/ago 2013. Disponível em: <http://ojs.ufgd.edu.br/index.php/educacao/article/view/2377>. Acesso em: jul. 2018.

PEIXOTO, A. G. O uso de metodologias ativas como ferramenta de potencialização da aprendizagem de diagramas de caso de uso. Periódico Científico Outras Palavras, v. 12, n. 2, 2016. Disponível em:

<http://revista.faculdadeprojecao.edu.br/index.php/Projecao5/article/view/718/604>. Acesso em: abr. 2019.

PINTO, D. D. O. Entenda a Importância e o Papel das Metodologias Ativas de Aprendizagem, 2019. Disponível em: <https://blog.lyceum.com.br/metodologias-ativas-deaprendizagem/>. Acesso em: abr 2019.

PRENSKY, M. Digital Native, digital immigrants. On the horizon, MCB University Press, vol. 9, n.5, octo, 2001. Disponível em:

<http://www.marcprensky.com/writing/Prensky\%20\%20Digital\%20Natives, \%20Digital\%20Im migrants\%20-\%20Part1.pdf>. Acesso em: mai. de 2020.

PRADO, A. F. et al., Ser Professor na Contemporaneidade: desafios da profissão. Saber Revista Eletrônica. Londrina: INESUL v. 21, n. 1 p. 1-13, jul./set. 2013. Disponível em: $\langle$ https://www.inesul.edu.br/revista/index.php?vol=25>. Acesso em: mai. 2020.

PRIMO, A. F. T. Interação Mútua e Interação Reativa. Revista FAMERCOS, São Paulo, n. 12, p. 81-92, jun. 2000.

REBELO, I. B. Interação entre homem e computador e procedimentos de avaliação. Brasilita: UNIEURO, 2010. Disponível em: < https://pt.scribd.com/document/19653938/IHCInteracao-entre-Homem-e-Computador-Apostila-TASI-IHC-2009-2 >. Acesso em: jan. 2018.

ROCHA, W. R. Interações Intermoleculares. Cadernos Temáticos de Química Nova na Escola, n. 04, p. 31-36, maio 2001. Disponível em:

<http://qnesc.sbq.org.br/online/cadernos/04/interac.pdf>. Acesso em: jan. 2019. 
SALLES, M. Interação e Interatividade em Educação. Revista Linha Direta, 16. ed. p. 46, fev. 2016. Disponível em: <https://linhadiretadigital.com.br/portal/\#/revistaDigital/1 >. Acesso em: abr 2019.

SILVA, M. Sala de aula interativa a educação presencial e à distância em sintonia com a era digital e com a cidadania: XXIV Congresso Brasileiro da Comunicação, p. 1-20 Anais (Online), Campo Grande: INTERCON, set. 2001.

SILVA, M. Cibercultura e educação: a comunicação na sala de aula presencial e online. Revista FAMERCOS, Porto Alegre, n 37, p. 69-74, dez. 2009. Disponível em:< https://revistaseletronicas.pucrs.br/ojs/index.php/revistafamecos/article/view/4802> Acesso em: jul.2020.

SOUZA, D. I. et al. Manual de Orientações para Projetos de pesquisa. Novo Hamburgo: FESLSVC, 2013. 55 p. Disponível em:

<http://www.liberato.com.br/sites/default/files/manualdeorientacoesparaprojetosdepesquisa.pdf $>$. Acesso em: mar. 2020.

VALENTE, J. A.; ALMEIDA, M. E. B.; GERALDINI, A. F. S. Metodologias ativas: das concepções às práticas em distintos níveis de ensino. Revista Diálogo Educacional, v. 17, n. 52, p. 455-478, out/dez 2017. Disponível em:

<https://www.redalyc.org/pdf/1891/189154955008.pdf>. Acesso em: mar. 2020.

VAN DAL, J. L. G. Convergências de Mídias: O Receptor como Protagonista do Processo Comunicacional: $9^{0}$ Interprogramas de Mestrado Faculdade Cásper Líbero. p. 1-20 Anais (online). São Paulo: Interprogramas, nov. 2013. Disponível em: < https://casperlibero.edu.br/wp-content/uploads/2014/04/Jorge-Luiz-Garcia-Van-Dal.pdf> Acesso em: jul. 2020.

VARGAS, L. M.; VARGAS, G. M.; CASTRO, G. J. D. Interatividade e a distância transacional na educação a distância: Um estudo preliminar. Simpósio Educacional de Educação a Distância / Encontro de Pesquisadores em Educação a Distância. São CarlosSP: [s.n.]. 2016. p. 1-9. Disponível em: <http://www.abed.org.br/congresso2016/trabalhos/159.pdf> Acesso em: mar 2019.

WITTACZIK, L. S. Ensino por Competências: possibilidades e limitações. Atos de Pesquisa em Educação-PPGE/ME FURB, Blumenau, v. 2, n. 1, p. 161-172, Jan/abr 2007. Disponível em: <https://proxy.furb.br/ojs/index.php/atosdepesquisa/article/view/163/125>. Acesso em: mar. 2019.

ZANETTI, L. A.; LUZIVOZOTTO, C. K. Interação, participação e deliberação online: o caso do website, Vote na Web. Cultura Midiática, Paraíba, n. 20, p. 132-146, jan-jun 2018. ISSN 1983-5930. Disponível em: 〈http://periodicos.ufpb.br/ojs2/index.php/cm>. Acesso em: jan. 2019.

Submetido em: 15 de maio de 2020 .

Aprovado em: 16 de julho de 2020. 